\title{
Key questions concerning paracetamol and NSAIDs for osteoarthritis
}

\section{P Courtney, M Doherty}

\section{Paracetamol has a pivotal role in the pharmacological treatment of symptomatic OA}

$\mathrm{E}$ xpert guidelines from both sides of the Atlantic have consistently recommended paracetamol, not nonsteroidal anti-inflammatory drugs (NSAIDs), as the initial oral drug treatment for osteoarthritis (OA) $\cdot{ }^{1-5}$ This has been justified by the excellent safety record and low cost of paracetamol relative to NSAIDs, and the absence of any significant clinical benefit of NSAIDs over simple analgesia. However, recent data from the USA suggest that NSAIDs may be better than paracetamol for symptom relief in large joint (hip, knee) OA. ${ }^{6-8}$ These data follow shortly after an unprecedentedly high profile launch and promotion of selective inhibitors of cyclo-oxygenase 2 (coxibs). The clinical benefit of coxibs in OA is equivalent to that of traditional NSAIDs, but coxibs do not have the increased risk of severe gastrointestinal (GI) side effects (peptic ulceration, bleeding, perforation, and obstruction). In America, particularly, these events have led to an intense debate about the relative role of NSAIDs, coxibs, and paracetamol in OA management. This review deals with key questions relating to such drug prescribing for the management of $\mathrm{OA}$.

\section{Is "which drug to use first" a relevant question?}

Although guidelines and reviews about the management of $\mathrm{OA}$ seem to be obsessed with this question, it probably has little relevance to clinical practice. Many patients treat themselves before consulting any doctor and have tried over the counter medicines that may include both paracetamol and NSAIDs. ${ }^{8}$ The concept of which drug to use first implies that monotherapy is the norm. However, most clinical trials of NSAIDs and coxibs allow concomitant paracetamol as "escape analgesia" and in a clinical setting a package of care is usually delivered. As rheumatologists largely see patients with OA only once and after a considerable delay, a more pertinent question for them may be "which drug, or drugs, are most appropriate and useful as the mainstay for long term symptom control in $\mathrm{OA}^{\prime \prime}$.

\section{Is which drug to use an important focus for discussion of $O A$ management?}

All guidelines agree that nonpharmacological measures should be central to the management plan of any patient with $\mathrm{OA}$, with pharmacological agents largely regarded as adjunctive optional treatments. ${ }^{1-5}$ Such core nonpharmacological measures include patient education, weight loss if obese, local strengthening and aerobic exercise, and biomechanical measures (such as pacing of activities and appropriate footwear) to avoid excessive loading of the OA joint. There is reasonable research evidence to support such "lifestyle" changes, ${ }^{1-69}$ all of which are safe, have excellent face validity, increase self efficacy, and may avoid, or reduce, the requirement for drug treatment.

\section{"Paracetamol should be tried before NSAIDs or coxibs"}

Unfortunately, undue emphasis on short term symptomatic tablets such as NSAIDs and coxibs may deflect attention from these more important long term measures, many of which may already be underused in patient management. Important though coxibs and NSAIDs may be from the perspective of the pharmaceutical industry, a prestigious document that focuses more than $25 \%$ of its text on the choice between paracetamol, NSAIDs, and coxibs ${ }^{6}$ is arguably giving the wrong message about global patient management.

\section{Is paracetamol effective for OA?}

Although paracetamol is widely recommended and used, research evidence for this is surprisingly scant. There has been only one placebo controlled trial of paracetamol in OA. Although it included just 25 patients with knee OA, it showed the greater efficacy of paracetamol..$^{10}$ Studies comparing NSAIDs with paracetamol in OA support its efficacy, ${ }^{71}{ }^{12}$ though these studies have omitted comparison with placebo. Paracetamol affords reasonable analgesia for postoperative acute pain, with a number needed to treat (NNT) of 4.6 for at least $50 \%$ pain relief compared with placebo. ${ }^{13}$ Although such efficacy cannot necessarily be extrapolated to the chronic pain associated with OA, the short term analgesic potential of paracetamol is well accepted.

\section{Are NSAIDs more effective than paracetamol for OA?}

Many NSAIDs have been shown to be more effective than placebo for symptom relief in OA when given orally or topically. Three randomised controlled trials compared paracetamol with NSAIDs for the symptomatic management of OA. ${ }^{711}{ }^{12}$ In a four week randomised, double blind trial in 184 patients with knee OA, Bradley et al showed that an antiinflammatory dose of ibuprofen (2400 $\mathrm{mg} /$ day) was no more effective in reducing pain and improving mobility than either a lower analgesic dose of ibuprofen (1200 mg/day) or paracetamol (4000 $\mathrm{mg} /$ day).${ }^{12}$ Clinical signs of joint "inflammation", specifically tenderness or swelling, did not predict a greater response to ibuprofen than to paracetamol, though the study was not well powered to show this. Williams et al performed a two year randomised, double blind trial of paracetamol $2600 \mathrm{mg} /$ day versus naproxen $750 \mathrm{mg} /$ day in 178 patients with knee OA. ${ }^{11}$ At six weeks patients randomised to naproxen had significant improvements in pain at rest, pain on motion, 50 foot $(15 \mathrm{~m})$ walk time, and doctor assessment, whereas those receiving paracetamol had significant improvements only in pain on motion and doctor assessment. However, only one third of patients completed the study and at two years the only outcome that favoured naproxen was improvement in the 50 foot walk time. The authors concluded that the efficacy of the two treatments was similar, though marginally better for naproxen. ${ }^{11}$ In a recent six week crossover trial of 218 patients with hip or knee OA comparing diclofenac/misoprostol 150 $\mathrm{mg} /$ day with paracetamol $4000 \mathrm{mg} /$ day, Pincus et al found that improvement in pain scores was significantly greater with diclofenac/misoprostol. ${ }^{7}$ In an accompanying editorial, Felson suggested that failure of the earlier trials to demonstrate greater efficacy for NSAID resulted from the smaller study size and the modest treatment effect of NSAID. From the reported data he calculated effect sizes of 0.3-0.4 favouring NSAIDs for pain relief. ${ }^{14}$

However, despite this reported statistical superiority of NSAIDs over paracetamol, two recent surveys have shown that more than $40 \%$ of patients with OA either prefer paracetamol rather than NSAIDs, or find no difference between the two ${ }^{815}$ (fig l). Furthermore, the proportion of those expressing preference for paracetamol increased with age. ${ }^{15}$ 


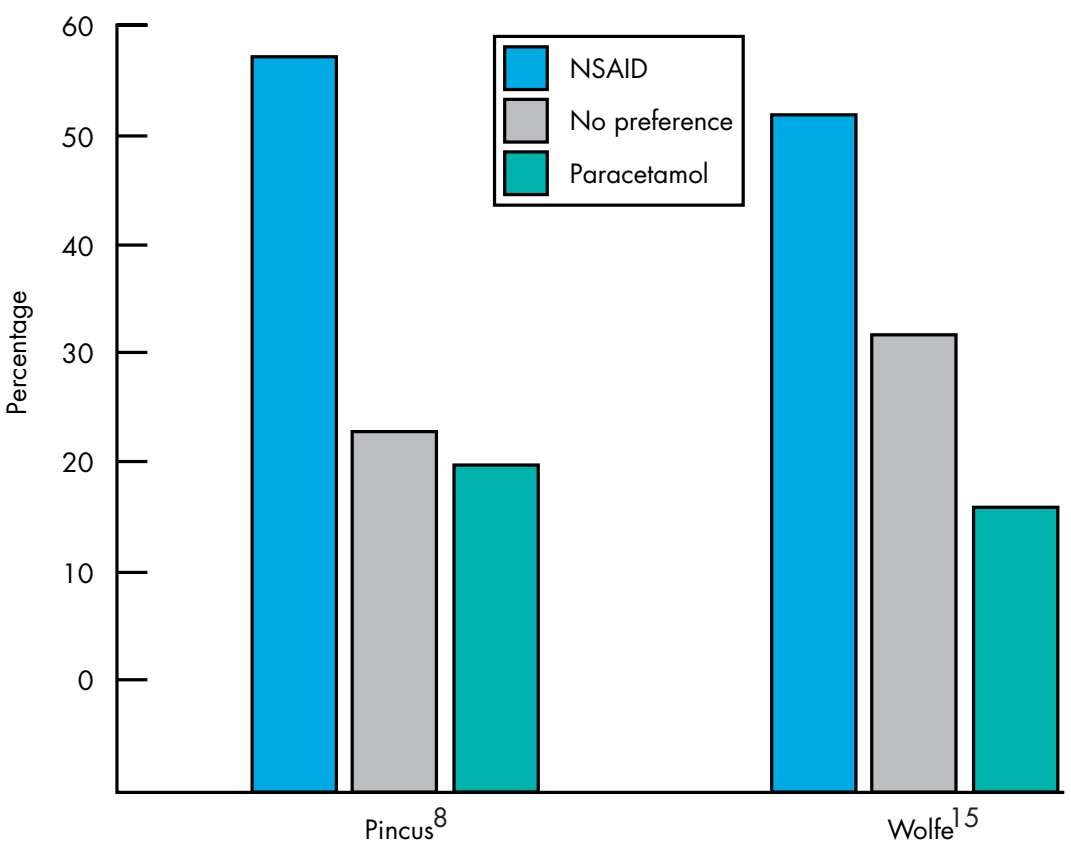

Figure 1 Histogram showing patient preference for NSAIDs or paracetamol for OA (adapted from Pincus et $a^{\beta}$ and Wolfe et $a^{15}{ }^{15}$. Both studies show that over $40 \%$ of patients either prefer paracetamol or did not express a preference.

Interestingly, the American authors of these studies interpreted the results as strongly favouring NSAID (a case of the glass half empty or half full). However, the absence of a clear perceived benefit

from NSAID in many patients with OA (almost half in these studies) argues against any policy to by-pass paracetamol on the basis of superior efficacy. Coxibs have been shown to have efficacy in $\mathrm{OA}$

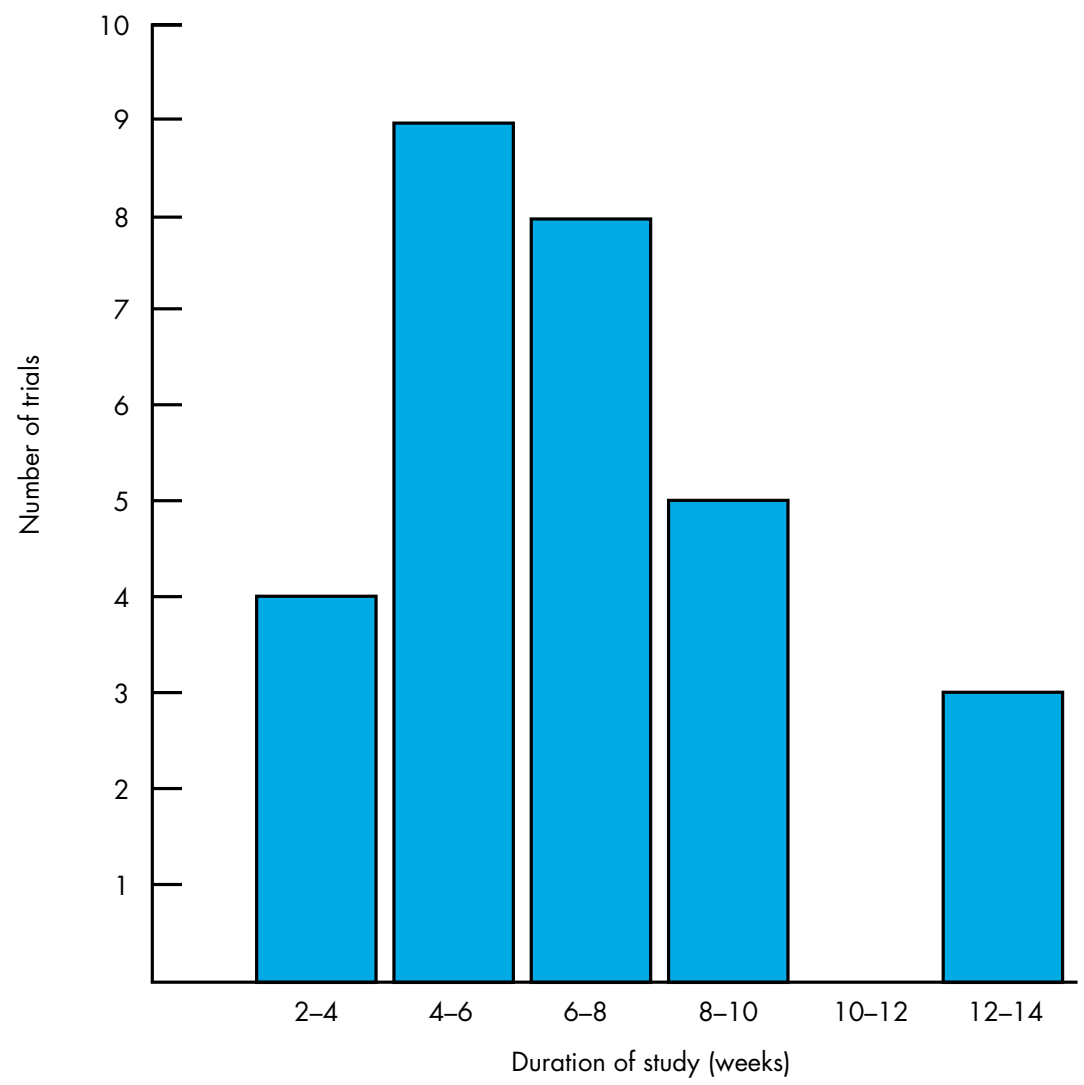

Figure 2 Histogram showing the duration of 29 randomised controlled trials of oral NSAIDs for $\mathrm{OA}$ (reproduced with permission from www.eBandolier). that is better than placebo and comparable with that of conventional NSAIDs. ${ }^{16}{ }^{17}$ One recent six week study comparing rofecoxib $(25 \mathrm{mg}$ or $12.5 \mathrm{mg}$ daily), celecoxib (200 mg/day), and acetaminophen ( $4 \mathrm{~g} /$ day) in 382 patients with knee OA has reported better efficacy for relief of pain during walking, rest pain, night pain, and morning stiffness in those taking $25 \mathrm{mg}$ rofecoxib, with both coxibs appearing stronger than acetaminophen. ${ }^{17 a}$ At six weeks a good or excellent response was reported by $4 / 10$ patients taking paracetamol, $5 / 10$ taking celecoxib, and 6/10 taking rofecoxib-a statistically significant but not over impressive clinical difference. The common caveats, discussed below, of short term treatment, the inclusion requirement of a "flare" after withdrawal of pre-study analgesia, and exclusion of patients with significant comorbidity all apply to this study. What magnitude of benefit can be
expected from NSAIDs and can we predict which patients will obtain additional benefit from oral NSAIDs relative to paracetamol?

The magnitude of benefit from NSAIDs in OA is usually modest with visual analogue scales typically improving by about $20 \mathrm{~mm}$ on a scale of $0-100 .^{18}$ Although large studies may show statistically significant group benefits, the individual gains are often trivial.

Clearly, some patients do obtain more benefit from NSAIDs than from paracetamol (and vice versa), but can we predict who they will be? The American College of Rheumatology (ACR) 2000 recommendations favour initial use of NSAIDs in patients with clinical features of inflammation and those with severe pain. ${ }^{6}$ However, data about whether NSAIDs are more effective than paracetamol for patients with OA with severe pain are conflicting, ${ }^{719}$ and clinical signs of inflammation or histological evidence of synovitis do not predict a better response to NSAIDs than paracetamol. ${ }^{12}$ The absence of evidence to substantiate such recommendations has led to criticism about the development and presentation of the ACR guidelines. ${ }^{20} 21$

\section{Are there issues concerning the design of clinical trials of NSAIDs in OA?}

In contrast with the paucity of randomised controlled trials of paracetamol, over half of all clinical trials in knee OA relate to NSAIDs. ${ }^{122}$ This primarily reflects the investment and marketing requirements of the pharmaceutical industry. ${ }^{22}$ Certain caveats that are common to these studies deserve emphasis. For example, most controlled trials of NSAIDs are short term with a median duration of just six weeks (fig 2), though longer trials of coxibs are in progress. 


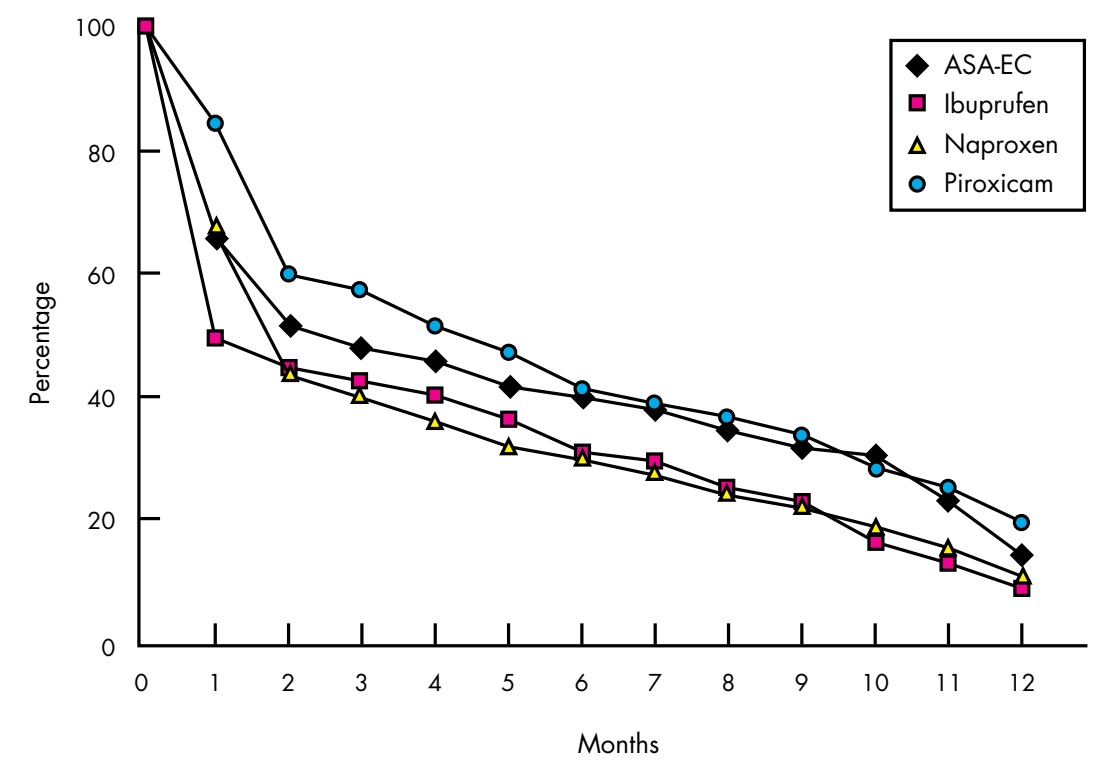

Figure 3 Graph showing discontinuation rates of four oral NSAIDs over a 12 month period (reproduced with permission from Scholes et $a^{24}$ ). ASA-EC, enteric coated aspirin.

Also, a recent strategy that has become popular, if not universal in industry sponsored studies, is to restrict recruitment to patients who demonstrate a "flare" (increase in pain) when their current analgesics, largely NSAIDs, are withdrawn. This, of course, results in selection bias towards patients who respond to oral drugs and reduces the generalisability of the results. Multiple additional exclusion criteria produce a homogeneous but unrepresentative study group that prevents examination of clinical predictors of response (for example, knee effusion, degree of radiographic change). Furthermore, paracetamol is often allowed as "rescue analgesia" to reduce drop-out rates, but the combined efficacy of NSAID and paracetamol is not specifically analysed. One trial that dealt with this issue ${ }^{23}$ showed that the efficacy of low dose naproxen plus paracetamol is comparable with that of high dose naproxen-in other words paracetamol had an "NSAID sparing" effect. However, whether higher dose NSAID plus paracetamol is better than either drug alone for more severe pain in OA has not been examined. Factorial study designs could efficiently address this issue.

\section{Why are long term results particularly important?}

OA is usually treated for years not weeks, so a long term perspective is clearly important when efficacy data are being considered. Unfortunately, in clinical practice the rate of NSAID discontinuation in patients with OA is high (fig 3), with only $10-15 \%$ of patients still taking their NSAID after 12 months. ${ }^{24}$ This reflects the patients' perspective of the usefulness of NSAIDs, taking into account the balance of efficacy and side effects. ${ }^{24}$ Even in the artificial setting of a clinical trial, two thirds of patients have discontinued treatment with oral NSAID or paracetamol by two years. ${ }^{11}$ Although it is suggested that NSAIDs more commonly are discontinued because of side effects and paracetamol because of perceived lack of efficacy, ${ }^{82}$ it is clear that the long term usefulness of both agents is less impressive than the short term data imply.

Long term data are also necessary for assessment of structural modification in $\mathrm{OA}$. A number of observations raise concern over the long term safety of NSAIDs on articular cartilage and bone in OA. For example:

- NSAIDs inhibit proteoglycan synthesis by articular cartilage in vitro ${ }^{25}$

- NSAIDs, especially indometacin, have been implicated in the acceleration of joint destruction in human hip and knee $\mathrm{OA}^{26} 27$

- NSAIDs effectively suppress heterotopic new bone formation after hip surgery, and may also inhibit reparative bone remodelling in $\mathrm{OA}^{28}$

The evidence implicating NSAIDs as a risk factor for radiographic progression in human OA is not without its caveats and requires confirmation. ${ }^{29}$ Nevertheless, no such concerns have been expressed for paracetamol, though clinical trials to establish its safety in this respect have not been undertaken.

\section{Are topical NSAIDs a safe and effective alternative to oral treatment?}

Topical NSAIDs are popular with patients and account for a significant proportion of global analgesic sales. They achieve only low blood levels and are very safe compared with oral NSAIDs. Short term trials, surveillance studies in general practice, ${ }^{30}$ and a record linkage case-control study ${ }^{31}$ all confirm their safety and show no association with GI bleeding. ${ }^{31}$ Although there has been scepticism about their efficacy, a quantitative systematic review in 1998 calculated a relative benefit of topical NSAID over placebo of 2.0 (95\% CI 1.5 to 2.7 ) and an $\mathrm{NNT}_{50}$ (number needed to treat to achieve $50 \%$ reduction in pain) of 3.1 (95\% CI 2.7 to 3.1 ). ${ }^{32}$ Significant superiority was demonstrated in seven of the 12 studies in this review, but in all 12 studies the proportion of patients with a successful outcome favoured topical NSAID (fig 4). Similar efficacy is reported when topical NSAID is compared with the parent or alternative oral NSAID. ${ }^{33}{ }^{34}$ The ability to substitute topical for oral NSAID has been demonstrated in one open study. ${ }^{35}$ Thus, good data support the safety and short term efficacy of topical NSAIDs for available joints such as the knee and hand, though again long term efficacy data (beyond two to four weeks) are lacking. In European guidelines topical NSAIDs are discussed on a par with oral NSAIDs ${ }^{1}$ and recommended as effective and safe for knee OA. ${ }^{3}$ In America, however, topical NSAIDs are not reimbursable and are thus largely disregarded in management recommendations. $^{56}$

\section{Is paracetamol safer than} conventional non-selective NSAIDs?

Conventional NSAIDs lead to significant mortality and morbidity from GI perforation, ulceration, and bleeding. ${ }^{36}$ Figure 5 shows the calculated mortality from NSAID associated GI events in the UK $^{37}$ compared with other causes of death. Other serious adverse effects include renal insufficiency, exacerbation of congestive heart failure, hyperkalaemia, and hypertension..$^{38}$ Many patients with $\mathrm{OA}$, of course, are elderly and have common comorbidities that make them particularly at risk from side effects and

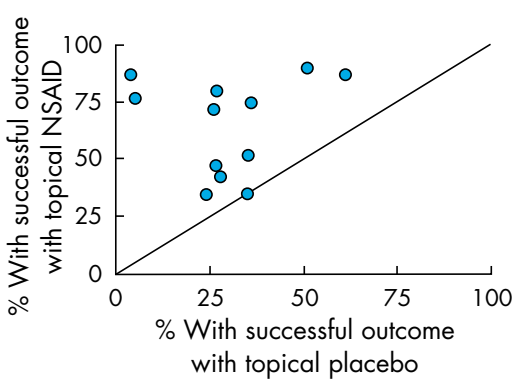

Figure 4 L'Abbé plot showing percentage of patients that achieved at least $50 \%$ pain relief from topical NSAIDs or placebo in 12 $O A$ trials (reproduced with permission from www.eBandolier). It is evident that all trials favour the active treatment. 


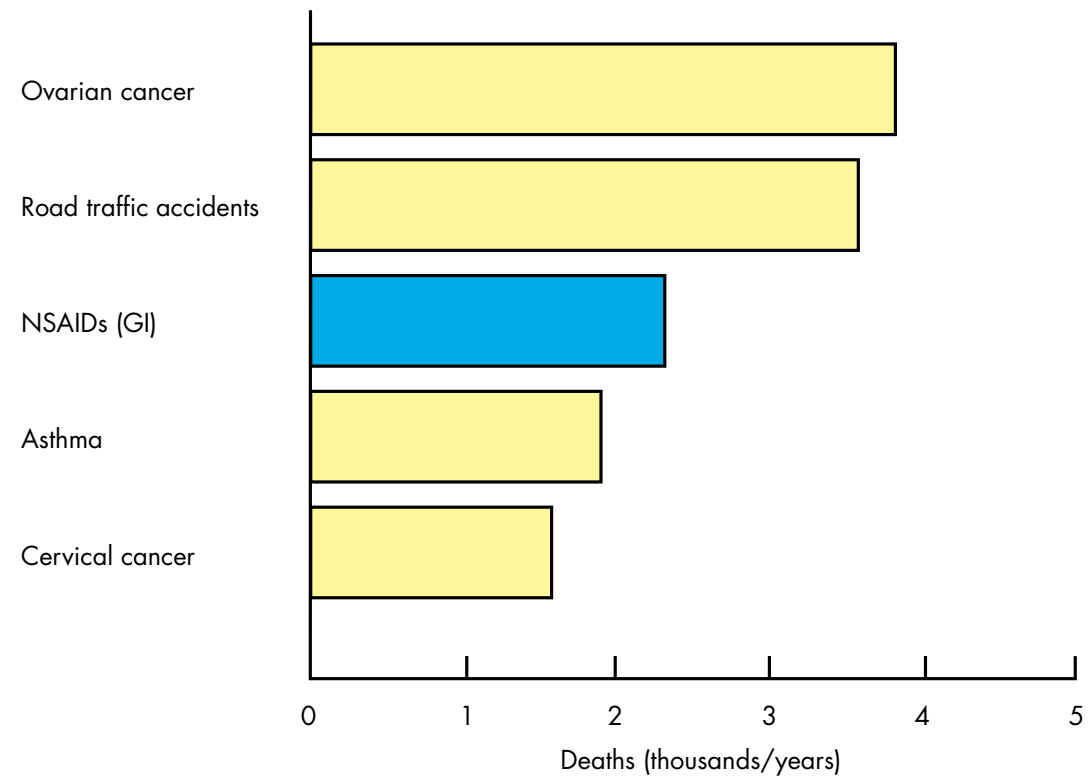

Figure 5 Gastrointestinal mortality associated with NSAIDs ${ }^{37}$ compared with other causes of death in the United Kingdom (Office for National Statistics 1997).

drug interactions from NSAIDs. In contrast, paracetamol at therapeutic dosage has an excellent safety record. ${ }^{40}$

\section{Are there significant safety concerns with paracetamol?}

Paracetamol has a narrow therapeutic/ toxicity range, so even a relatively modest overdose may be associated with fatal hepatic toxicity ${ }^{41}$ Although some reports suggest that therapeutic doses of paracetamol may cause liver toxicity in those who drink excess alcohol, ${ }^{41}$ other studies support the safety of paracetamol in therapeutic doses in patients with established liver disease, making it the preferred analgesic, certainly over NSAIDs, in those with chronic liver disease. ${ }^{42}$ Similarly, although there have been rare reports of renal impairment with paracetamol, ${ }^{43}$ these are placed in perspective by the Scientific Advisory Board of the National Kidney Foundation, which recommends paracetamol as the preferred analgesic in patients with renal impairment. ${ }^{44}$

Paracetamol is thought to work mainly through inhibition of central cyclo-oxygenase (COX) with only very weak effects on peripheral prostaglandin synthesis. ${ }^{45}$ However, there have been recent reports of two new possible adverse effects that might relate to peripheral COX inhibition. Firstly, one UK case-control study suggested that frequent (weekly or daily) paracetamol may be associated with asthma and rhinitis $^{46}$ (discussed below). Secondly, and perhaps more importantly, a record linkage study using an automated UK database suggested that paracetamol has dose dependent GI toxicity. ${ }^{47}$ However, these data were generated as a byproduct of a study examining the safety of newer NSAIDs in which paucity of data prevented conclusions. They may be confounded by inability to account fully for concomitant drug usage and are counter to other epidemiological evidence that shows no GI risk from paracetamol. ${ }^{48}$ Furthermore, although paracetamol has an additive effect on ibuprofen-induced gastric erosions in rats, ${ }^{49}$ it has not been shown to cause gastroduodenal injury in human trials. ${ }^{50}$ Nevertheless, despite the balance of evidence supporting no significant GI toxicity from paracetamol further studies to specifically deal with this issue are underway.

\section{Are concerns about NSAID associated GI toxicity eliminated by coxibs or combination with gastroprotective agents?}

Coxibs are associated with an incidence of GI ulceration that is comparable with placebo, and a reported reduced risk of clinically relevant events (complicated and symptomatic ulcers) compared with traditional NSAIDs over a 6-9 month period. ${ }^{5152}$ There is good evidence that rofecoxib significantly reduces the risk of complicated ulcers compared with naproxen. ${ }^{51}$ However, the evidence for celecoxib relates to preliminary (six month) pooled data from two longer studies comparing celecoxib with either ibuprofen (2400 mg/day) or diclofenac (150 mg/day). This ("CLASS") study ${ }^{52}$ combined data for both complicated and symptomatic ulcers and showed fewer events in the celecoxib group than in the two NSAID groups. However, the unpublished full results of both studies presented to the FDA showed no advantage for celecoxib at 12 or 16 months..$^{53}$ Although these studies might have been confounded by concomitant use of low dose aspirin, ${ }^{52}$ the long term advantage of this coxib with respect to GI ulcer complications remains in question. The combined use of either misoprostol or proton pump inhibitors ("gastroprotection") with NSAIDs significantly reduces NSAID associated GI complication rates. $^{5455}$

Nevertheless, despite their reported safety, less serious dyspepsia may still occur with coxibs and this might have an impact on quality of life and costs due to additional doctor visits and investigations. A direct comparison of the incidence of troublesome non-specific GI side effects from coxibs, conventional NSAIDs, paracetamol, and placebo has not been reported in the same population.

\section{Are COX-2 specific inhibitors as safe as paracetamol?}

Paracetamol and coxibs have not been directly compared in clinical trials. In patients with renal impairment, paracetamol is the preferred analgesic, ${ }^{44}$ but there are concerns about coxibs, perhaps more with rofecoxib than celecoxib. ${ }^{56}$ Paracetamol has only one drug interaction, with high dose warfarin, ${ }^{57}$ but NSAIDs and coxibs have multiple drug interactions. ${ }^{58}$ The only safety factor in favour of coxibs is that they appear to be relatively safe at supratherapeutic (though not necessarily "overdose") levels, whereas paracetamol is potentially fatal in overdose.

\section{Which drug is preferred in patients with OA and asthma?}

Non-selective NSAIDs are associated with serious drug induced bronchospasm (aspirin-induced asthma). ${ }^{59}$ The likely mechanism is COX inhibition, diverting arachidonic acid metabolites to the lipoxygenase pathway with a resultant increase in leucotriene synthesis. ${ }^{60}$ There is accumulating evidence that rofecoxib does not induce bronchospasm in patients with documented aspirininduced asthma. ${ }^{60}{ }^{61}$ Paracetamol has not been linked to acute bronchospasm. However, one case-control study reported a graded association between paracetamol and asthma with daily users of paracetamol having an odds ratio for asthma of 2.38 (95\%CI 1.22 to 4.64 ) compared with never users. ${ }^{46}$ There are caveats to such a case-control study, including the fact that self reported drug use was current rather than retrospective (premorbid), though the authors did not think that avoidance by patients with asthma of aspirin and NSAIDs in favour of paracetamol explained this association. Although weak inhibition of COX- 1 and COX- 2 by paracetamol ${ }^{45}$ and reduction of lung glutathione antioxidant levels ${ }^{46}$ might theoretically predispose to 
asthma, a causal link first needs to be established, ideally in a prospective study.

\section{Is the absence of an antiplatelet effect with coxibs an advantage in patients with OA?}

The absence of antiplatelet activity (resulting from COX-1 inhibition) with coxibs was initially considered advantageous because it might further reduce the risk of GI bleeding and allow coxibs to be used more safely with anticoagulants. ${ }^{62}$ However, this antiplatelet effect might be advantageous in patients with OA who predominantly are elderly with frequent comorbidity such as obesity and thus often at higher risk of cerebrovascular or ischaemic heart disease. This indeed is supported by the increased rate of myocardial infarction seen with selective COX-2 inhibition (rofecoxib) compared with non-selective COX inhibition (naproxen). ${ }^{50}{ }^{63}$ Paracetamol has no significant effects on platelets so this issue only relates to comparisons between coxibs and NSAIDs.

\section{Which drugs are most cost effective?} Management costs will continue to be an important factor in a condition as prevalent as OA. There is no doubt that paracetamol, with its low purchase cost, low incidence of side effects, and reasonable efficacy, is the cheapest pharmacological option for OA. Many patients even bear the purchase cost themselves. Debate continues about the cost effectiveness of the more expensive coxibs relative to conventional NSAIDs, the principal economic justification for coxibs being the avoidance of serious and expensive adverse GI events. ${ }^{64}$ However, paracetamol is clearly the preferred drug when economic factors are considered. ${ }^{21}$

\section{What factors influence analgesic prescribing for individual patients with OA?}

Management of a patient with OA needs to be individualised and patient centred. ${ }^{1}$ Factors that need to be taken into account include:

- The balance of efficacy and side effects of appropriate evidence based interventions

- The costs, availability, and logistics of treatment delivery

- The presence of comorbid disease and its treatment

- Drugs and coping strategies already tried by the patient

- The patient's daily activity requirements and work and recreational aspirations

- The patient's perceptions and knowledge of OA and its treatment.

The patient's perspective is crucial to any success or adherence to treatment.

\section{Key clinical points concerning NSAIDs and paracetamol for OA}

Management must be individualised and patient-centred. Debate about NSAIDs and coxibs should not distract attention from the more important non-pharmacological interventions that are central to any long term management plan.

\section{Efficacy}

- Paracetamol and NSAIDs are evidence based drugs for symptom relief in OA, but benefits are often modest and long term adherence is poor. Coxibs have only equal (not better) efficacy to non-selective NSAIDs.

- NSAIDs give more pain relief to some patients with OA, but others (almost half those studied) find paracetamol either better than NSAIDs or equally effective.

- There are no recognised clinical predictors of response to NSAIDs or paracetamol.

- Advice alone, with or without simple non-drug measures or over the counter drugs, allows many chronic NSAID users to stop their NSAID without a problem.

- Common caveats to NSAID/coxib trials in OA (for example, selection bias, short term outcomes, non-attributed escape analgesia) reduce the generalisability of the results.

- Topical NSAIDs are effective, popular with patients, and probably underused.

\section{Safety and costs}

- Many patients with OA are elderly and have comorbid disease. They are often at highest risk of NSAID associated side effects (GI, renal, cardiovascular) and drug interactions.

- Paracetamol at therapeutic doses has an excellent safety record compared with oral NSAIDs and coxibs.

- Paracetamol is the preferred analgesic in patients with renal impairment, chronic liver disease, hypertension, chronic heart failure, or aspirin-induced asthma.

- The use of coxibs, or NSAIDs plus gastroprotection, greatly reduces morbidity/ mortality from GI toxicity. Topical NSAIDs are very safe and have no Gl toxicity.

- The antiplatelet activity (COX-1 inhibition) associated with non-selective NSAIDs may result in less cardiovascular mortality with NSAIDs than with coxibs.

- Paracetamol is very much cheaper than NSAIDs and coxibs.

Patients often perceive paracetamol to be either too mild, because of its availability, or too dangerous, because of its toxicity in overdose, and worry that benefits diminish with regular use. They may believe that treatment has "failed" with paracetamol after taking only a suboptimal dose or frequency. Such perceptions require open and full discussion. Equally, the potential benefits and side effects of NSAIDs, coxibs, or other agents require full discussion before a trial of such treatment is mutually agreed.

Common sense dictates that simple and safe interventions are tried first before more complex, expensive, or potentially dangerous interventions. A step-up, additive approach is most usual for control of chronic pain. The patient's symptoms and requirements will alter with time and in response to treatment, requiring review and re-adjustment rather than rigid continuation of a single algorithm. Paracetamol, topical NSAID, and either oral non-selective NSAIDs or coxibs may all legitimately be used singly or in combination in individual patients. However, from the issues discussed above, it would seem irrational if paracetamol were not given an appropriate trial before oral NSAIDs or coxibs. If good benefit is obtained paracetamol should remain the principal oral treatment. ${ }^{1}$ If definite, but insufficient relief is obtained other oral or topical agents may be tried in addition. If paracetamol or any drug gives no relief it should be abandoned and other options tried.

\section{Can NSAID prescribing be reduced in OA?}

A reverse strategy to assess the clinical usefulness of a drug is to examine the effects of its withdrawal and the ease with which alternative simpler measures compensate for its absence. Black et al found it possible to withdraw NSAIDs successfully from elderly patients who were regular NSAID users; six months later about $50 \%$ had not required the NSAID to be restarted. ${ }^{65}$ Jones et al similarly reported easy withdrawal of NSAIDs in $75 \%$ of elderly patients with acute disease admitted to hospital, most of whom had medical conditions possibly caused by, or aggravated by, NSAIDs. ${ }^{66}$ Primary care doctors reportedly prefer oral NSAIDs rather than paracetamol in the management of $\mathrm{OA}^{67}$ and because most NSAID prescriptions are initiated in primary care, it is here that intervention might most improve the appropriateness of NSAID prescribing. A recent randomised controlled trial undertaken in primary care in Nottingham, UK, found that for chronic NSAID users, including those with OA, a nursedelivered education intervention resulted in an additional $28 \%$ of patients in the intervention group either stopping their NSAID or reducing the dosage by 
$>50 \%$ at six months compared with controls. ${ }^{68}$ Importantly, this was not detrimental to the patients' symptoms, function, or quality of life. Such an intervention involving advice and, if needed, simple alternative non-drug and over the counter treatments, would be cost effective if continued long term. ${ }^{68}$

March et al used "n of 1 " trials to determine the comparative efficacy of paracetamol and oral NSAIDs within individual patients with OA. ${ }^{69}$ As with later studies ${ }^{715}$ they could not demonstrate clear overall superiority for NSAIDs, and at six months OA in almost half their patients was well controlled by paracetamol. They suggested that such individual trials might be used more often in clinical care to reduce unnecessary NSAID prescribing. ${ }^{69}$

\section{Conclusions}

As commented in the EULAR Recommendations, ${ }^{1}$ there is often discordance between research evidence and expert opinion. Interestingly, much of our practice appears to be governed more by clinical experience and individual bias than by the balance of published evidence. Pharmaceutical companies may have a persuasive role in shaping this bias. $^{21}{ }^{22}$ However, at least from a UK European perspective (bias) we conclude the following:

- Non-pharmacological interventions should be the core element of any management plan

- Paracetamol is more efficacious than placebo and has comparable efficacy to NSAIDs for many patients with OA

- Paracetamol has an excellent safety record

- In view of its efficacy, safety, and cost effectiveness paracetamol should retain its pivotal role in the drug treatment of symptomatic OA

- The addition of topical NSAIDs, coxibs, or traditional NSAIDs (and other pharmacological agents) should be considered, depending on the response to paracetamol (and other interventions) and on individual patient factors.

Ann Rheum Dis 2002;61:767-773

\section{Authors' affiliations}

P Courtney, M Doherty, Academic

Rheumatology, Clinical Sciences Building, City

Hospital, Nottingham NG5 1PB, UK

Correspondence to: Professor M Doherty; Michael.Doherty@nottingham.ac.uk

\section{REFERENCES}

1 Pendleton A, Arden N, Dougados D, Doherty

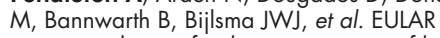
recommendations for the management of knee osteoarthritis: report of a task force of the Standing Committee for International Clinical
Studies Including Therapeutic Trials (ESCISIT) Ann Rheum Dis 2000;59:936-44.

2 Scott DL. Guidelines for the diagnosis, investigation and management of osteoarthritis of the hip and knee. Report of a Joint Working Group of the British Society for Rheumatology and the Research Unit of the Royal College of Physicians. J R Coll Physicians Lond 1993;27:391-6.

3 Walker-Bone K, Javaid K, Arden N, Cooper C. Medical management of osteoarthritis. BMU 2000;321:936-40.

4 Hochberg MC, Altman RD, Brandt KD, Clark BM, Dieppe PA, Griffen MR, et al. Guidelines for the medical management of osteoarthritis. Part I. Osteoarthritis of the hip. Arthritis Rheum 1995:38:1535-40.

5 Hochberg MC, Altman RD, Brandt KD, Clark BM, Dieppe PA, Griffen MR, et al. Guidelines for the medical management of osteoarthritis. Part II. Osteoarthritis of the knee. American College of Rheumatology. Arthritis Rheum 1995;38:1541-6

6 American College of Rheumatology Subcommittee on Osteoarthritis Guidelines. Recommendations for the medical management of osteoarthritis of the hip and knee: 2000 update. Arthritis Rheum 2000;43:1905-15.

7 Pincus T, Koch GG, Sokka T, Lefkowith J, Wolfe F, Jordan JM, et al. A randomized, double-blind, crossover clinical trial of diclofenac plus misoprostol versus acetaminophen in patients with osteoarthritis of the hip or knee. Arthritis Rheum 2001;14:1587-98.

8 Pincus T, Swearingen C, Cummins $P$ Callahan LF. Preference for nonsteroidal antiinflammatory drugs versus acetaminophen and concomitant use of both types of drugs in patients with osteoarthritis. J Rheumatol 2000;27: 1020-7.

9 Felson DT (chair). Osteoarthritis: new insights. Ann Intern Med 2000;133:726-7.

10 Amadio P, Cummings DM. Evaluation of acetaminophen in the management of osteoarthritis of the knee. Curr Ther Res 1983;34:59-66.

11 Williams HJ, Ward JR, Egger M, Neuner R Brooks RH, Clegg DO, et al. Comparison of naproxen and acetaminophen in a two-year study of treatment of osteoarthritis of the knee. Arthritis Rheum 1993;36:1 196-206.

12 Bradley JD, Brandt KD, Katz BP, Kalasinski LA, Ryan SI. Treatment of knee osteoarthritis: relationship of clinical features of joint inflammation to the response to a nonsteroidal antiinflammatory drug or pure analgesic. J Rheumatol 1992;19:1950-4

13 Moore A, Collins S, Carroll D, McQuay H. Paracetamol with and without codeine in acute pain: a quantitative systematic review. Pain 1997;70:193-201.

14 Felson DT. The verdict favours nonsteroidal antiinflammatory drugs for treatment of osteoarthritis and a plea for more evidence on other treatments. Arthritis Rheum 2001;44:1477-80

15 Wolfe F, Zhao S, Lane N. Preference for nonsteroidal antiinflammatory drugs over acetaminophen by rheumatic disease patients. Arthritis Rheum 2000;43:378-85.

16 Ehrlich EW, Schnitzer TJ, Mcllwaine H, Levy $\mathrm{R}$, Wolfe F, Weisman M, et al. Effect of specific COX-2 inhibition in osteoarthritis of the knee: a 6 week double blind, placebo controlled pilot study of rofecoxib. J Rheumato 1999;26:2438-47.

17 Bensen WG, Fiechtner JJ, McMillen JI, Zhao WW, Yu SS, Woods EM, et al. Treatment of osteoarthritis with celecoxib, a cyclooxygenase-2 inhibitor: a randomised controlled trial. Mayo Clin Proc 1999;74: 1095-105.

17a Geba $\mathbf{P}$, Weaver AL, Polis AB, Dixon ME, Schnitzer TJ. Efficacy of rofecoxib, celecoxib and acetaminophen in osteoarthritis of the knee. JAMA 2002;287:64-71.

18 Tyson VCH, Glynne A. A comparative study of benoxaprofen and ibuprofen in osteoarthritis in general practice. J Rheumatol 1980;7(suppl 6):132-8.
19 Bradley JD, Katz BP, Brandt KD. Severity of knee pain does not predict a better response to an antiinflammatory dose of ibuprofen than to analgesic therapy in patients with osteoarthritis. J Rheumatol 2001:28:1073-6.

20 Brandt KD. A critique of the 2000 update of the American College of Rheumatology recommendations for management of hip and knee osteoarthritis. Arthritis Rheum 2001:44:2451-5.

21 Brandt KD, Bradley JD. Should the initial drug used to treat osteoarthritis pain be a nonsteroidal antiinflammatory drug? J Rheumatol 2001;28:467-73.

22 Chard JA, Tallon DJ, Dieppe PA Epidemiology of research into interventions for the treatment of osteoarthritis of the knee joint. Ann Rheum Dis 2000;59:414-18

23 Seideman P, Samuelson P, Neander G. Naproxen and paracetamol compared with naproxen only in coxarthrosis: increased effect of the combination in 18 patients. Acta Orthop Scand 1993;64:285-8.

24 Scholes D, Stergachis A, Penna PM, Normand EH, Hansten PD. Nonsteroidal anti-inflammatory drug discontinuation in patients with osteoarthritis. J Rheumatol 1995;22:708-12.

25 Brandt KD. Effects of nonsteroidal anti-inflammatory drugs on chondrocyte metabolism in vitro and in vivo. Am J Med 1987;83:29-34

26 Rashad S, Revell P, Hemingway A, Low F, Rainsford K, Walker F. Effect of non-steroidal anti-inflammatory drugs on the course of osteoarthritis. Lancet 1989;ii:519-22.

27 Huskisson EC, Berry H, Gishen P, Jubb RW, Whitehead J. Effects of anti-inflammatory drugs on the progression of osteoarthritis of the knee. J Rheumatol 1995;22:1941-6.

28 Neal BC, Rodgers A, Clark T, Gray H, Reid IR, Dunn L, et al. A systematic survey of 13 randomized trials of non-steroidal antiinflammatory drugs for the prevention of heterotopic bone formation after major hip surgery. Acta Orthop Scand 2000;71:122-8.

29 Doherty $\mathbf{M}$, Jones A. Indomethacin hastens large joint osteoarthritis in humans - how strong is the evidence? J Rheumatol 1995;22:2013-16.

30 Newbery R, Shuttleworth P, Rapier C. A multicentre post marketing surveillance study to evaluate the safety and efficacy of felbinac $3 \%$ gel in the treatment of musculoskeletal disorders in general practice. Eur J Clin Res 1992;3:139-50.

31 Evans JMM, McMahon AD, McGilchrist MM White G, Murray FE, McDevitt DG, et al. Topical non-steroidal anti-inflammatory drugs and admission to hospital for upper gastrointestinal bleeding and perforation: a record linkage case-control study. BM 1995;311:22-6.

32 Moore RA, Tramer MR, Carroll D, Wiffen PJ, McQuay HJ. Quantitative systematic review of topically applied non-steroidal anti-inflammatory drugs. BM 1998;316:333-8.

33 Dickson DJ. A double-blind evaluation of topical piroxicam gel with oral ibuprofen in osteoarthritis of the knee. Curr Ther Res 1991;49:199-207.

34 Sandelin J, Harilainen A, Crone $\mathrm{H}$, Hamberg P, Forsskahl B, Tamelander G. Local NSAID gel (eltenac) in the treatment of osteoarthritis of the knee. A double blind study comparing eltenac with oral diclofenac and placebo gel. Scand J Rheumatol 1997;26:287-92.

35 Browning RC, Johnson K. Reducing the dose of oral NSAIDs by use of feldene gel: an open study in elderly patients with osteoarthritis. Adv Ther 1994;11:198-207.

36 Wolfe MM, Lichtenstein DR, Singh G. Gastrointestinal toxicity of nonsteroidal antiinflammatory drugs. N Engl J Med 1999:340: 1888-99.

37 Tramer MR, Moore RA, Reynolds DJ, McQuay HJ. Quantitative estimation of rare adverse events which follow biological progression:a new model applied to chronic NSAID use. Pain 2000;85: 169-82.

38 Page J, Henry D. Consumption of NSAIDs and the development of congestive heart 
failure in elderly patients. An under recognised public health problem. Archiv Intern Med 2000; 160:777-84.

39 Sandler DP, Burr FR, Weinburg CR. Nonsteroidal anti-inflammatory drugs and risk of chronic renal disease. Ann Intern Med 1991;115:165-72.

40 Clissold SP. Paracetamol and phenacetin. Drugs 1986;32:46-59.

41 Whitcomb DC, Block GD. Association of acetaminophen hepatotoxicity with fasting and ethanol use. JAMA 1994;273:1845-50

42 Lynch JM, Fox TM. Use of acetaminophen in the treatment of osteoarthritis in patients with liver disease: comment on the 2000 update of the ACR recommendations for management of hip and knee osteoarthritis. Arthritis Rheum 2001;44:2448-60

43 Sandler DP, Burr FR, Weinburg CR. Analgesic use and chronic renal disease. $\mathrm{N}$ Engl J Med 1989;320:1238-43.

44 Henrich WL, Agodaoa LE, Barrett B. Analgesics and the kidney: summary and recommendations to the Scientific Advisory Board of the National Kidney Foundation. Am J Kidney Dis 1996;27:162-5.

45 Warner TD, Giuliano F, Vojnovic I, Bukasa A, Mitchell JA, Vane JR, et al. Non steroid drug selectivities for cyclooxygenase- 1 rather than cyclooxygenase-2 are associated with human gastrointestinal toxicity: a full in vitro analysis. Proc Natl Acad Sci USA 1999;96:7563-8.

46 Shaheen SO, Sterne JAC, Songhurst CE, Burney PG. Frequent paracetamol use and asthma in adults. Thorax 2000;55:266-70.

47 Garcia Rodriguez LA, Hernandez-Diaz S. Relative risk of upper gastrointestinal complications among users of acetaminophen and nonsteroidal anti-inflammatory drugs. Epidemiology 2001;12:570-6.

48 Langman MJS, Weil J, Wainwright $P$, Lawson DH, Rawlins MD, Logan RFA, et al. Risks of bleeding peptic ulcer associated with individual non-steroidal anti-inflammatory drugs. Lancet 1994;343:1075-8.

49 Bhattacharya SK, Goel RK, Bhattacharya SK, Tandon R. Potentiation of gastric toxicity of ibuprofen by paracetamol rat. J Pharm Pharmacol 1991;43:520-1.

50 Lanza FL, Codispoti JR, Nelson EB. An endoscopic comparison of gastroduodenal injury with over the counter doses of ketoprofen and acetaminophen. Am J Gastroenterol 1998;93:1020-2.

51 Bombardier C, Laine L, Reicin A, Shapiro D, Burgos-Vargas R, Davis B, et al. Comparison of upper gastrointestinal toxicity of rofecoxib and naproxen in patients with rheumatoid arthritis. N Engl J Med 2000;343:1520-8.

52 Silverstein FE, Faich G, Goldstein JL, Simon LS, Pincus T, Whelton A, et al. Gastrointestinal toxicity with celecoxib versus nonsteroidal anti-inflammatory drugs for osteoarthritis and rheumatoid arthritis. JAMA 2000;284: 1247-55

53 Hrachovec JB. Reporting of 6-month vs 12 month data in a clinical trial of celecoxib. JAMA 2001;286:2398.

54 Silverstein FE, Graham DY, Senior JR, Davies HW, Struthers BJ, Bittman RM, et al. Misoprostol reduces serious gastrointestinal complications in patients with rheumatoid arthritis receiving non steroidal anti-inflammatory drugs. A randomized, double-blind, placebo-controlled trial. Ann Intern Med 1995;123:241-9.

55 Yeomans ND, Tulassay Z, Juhasz L, Racz I, Howard JM, van Rensburg CJ, et al. A comparison of omeprazole with ranitidine for ulcers associated with non-steroidal anti-inflammatory drugs. $\mathrm{N}$ Engl J Med 1998;338:719-26.

56 Whelton A, Fort JG, Puma JA, Normandin D, Bello AE, Verburg KM. Cyclooxygenase-2specific inhibitors and cardiorenal function: a randomized, controlled trial of celecoxib and rofecoxib in older hypertensive osteoarthritis patients. Am J Ther 2001;8:85-95.

57 Hylek M, Heiman H, Skates SJ, Sheehan MA, Singer DE. Acetaminophen and other risk factors for excessive warfarin anticoagulation. JAMA 1998;279:657-62.

58 Garnett WR. Clinical implications of drug interactions with coxibs. Pharmacotherapy 2001;21:1223-32.
59 Leuppi JD, Schnyder P, Hartmann K, Reinhart WH, Kuhn M. Drug-induced bronchospasm. Respiration 2001;68:345-51.

60 Stevenson DD, Simon RA. Lack of cross-reactivity between rofecoxib and aspirin in aspirin-sensitive patients with asthma. Allergy Clin Immunol 2001;108:47-51.

61 Szezeklik A, Nizankowska E, Bochenek G, Nagraba K, Mejza F, Swierczynska M. Safety of a specific COX-2 inhibitor in aspirin-induced asthma. Clin Exp Allergy 2001;31:179-81.

62 Karim A, Tolbert D, Piergies A, Hubbard RC, Harper K, Wallemark CB, et al. Celecoxib does not significantly alter the pharmacokinetics or the hypoprothrombinemic effect of warfarin in healthy subjects. J Clin Pharmacol 2000:40:655-63.

63 Mukherjee D, Nissen SE, Topol EJ. Risk of cardiovascular events associated with selective COX-2 inhibitors. JAMA 2001;286:954-9.

64 Peloso PM, Scheiman JM. The economic implications of cyclooxygenase-2-specific inhibitors. Am J Med 2001;1 10:50-4S.

65 Black D, Tuppen J, Heller A. NSAID withdrawal in elderly patients. J Am Geriatr Soc 1991;39:52.

66 Jones AC, Berman P, Doherty M. Non-steroidal anti-inflammatory drug usage and requirement in elderly acute hospital admissions. Br J Rheumatol 1992;31:45-8.

67 Keys J, Beardon PH, Lau C, Lang CC, McDevitti DG. General practioners use of non-steroidal anti-inflammatory drugs in Tayside and five regions. J Soc Med 1992;85:422-5

68 Jones AC, Coulson L, Muir K, Tolley K, Lophatananon A, Everitt L, et al. A nurse-delivered advice intervention can reduce chronic non-steroidal anti-inflammatory drug use in general practice: a randomised controlled trial. Rheumatology (Oxford) 2002;40: 14-21.

69 March L, Irwig L, Schwarz J, Simpson J, Chock C, Brooks P. N of 1 trials comparing a non-steroidal anti-inflammatory drug with paracetamol in osteoarthritis. BM 1994;309: 1041-6. 